\title{
Behavioural and structural prevention to promote the health of socially disadvantaged children and adolescents: an overview of European and German health promotion strategies
}

\author{
S. Pawils • A. Atabaki • F. Metzner • G. Nöcker • \\ S. Linden • M. Plaumann $\cdot$ U. Walter
}

Received: 12 September 2011 / Accepted: 14 December 2011 / Published online: 13 January 2012

(C) Springer-Verlag 2012

\section{Introduction}

Childhood and adolescence are significant phases in life, characterized by many physical and psychosocial changes. Diseases and health related attitudes during these sensitive stages of life have a significant and lifelong impact, not only on health issues, but also on the overall development (Kuh and Ben-Schlohmo 2005; Power and Kuh 2006). The early

S. Pawils - A. Atabaki

Institut für Medizinische Psychologie (Institute of Medical

Psychology), Universitätsklinikum Hamburg-Eppendorf

(University Medical Center Hamburg-Eppendorf),

Hamburg, Germany

\section{F. Metzner}

Child Public Health Research Department,

Universitätsklinikum Hamburg-Eppendorf

(University Medical Center Hamburg-Eppendorf),

Hamburg, Germany

G. Nöcker $\cdot$ S. Linden

Bundeszentrale für gesundheitliche Aufklärung

(Federal Centre for Health Education),

Cologne, Germany

M. Plaumann · U. Walter

Institut für Epidemiologie, Sozialmedizin und

Gesundheitssystemforschung (Institute for Epidemiology, Social

Medicine and Health Systems Research), Medizinische

Hochschule Hannover (Hannover Medical School),

Hannover, Germany

S. Pawils $(\bowtie)$

Zentrum für Psychosoziale Medizin, Institut und

Poliklinik für Medizinische Psychologie,

Universitätsklinikum Hamburg-Eppendorf,

Martinistr. 52 (W26),

20246 Hamburg, Germany

e-mail: s.pawils@uke.de experience of health inequalities is a major risk factor for children's and adolescents' further health development. Thus, the early and efficient prevention of ill-health behaviours (behavioural prevention) and in relevant social settings (structural prevention) among children and young people, particularly those who are socially disadvantaged, is crucial.

Social disadvantage in Germany

Defining social disadvantage is complicated. While some definitions emphasize meeting the mental and physical basic needs (Biermann and Rützel 1999), others focus on power and social discrimination (Iben 1997). Most empirical studies, however, define social disadvantage by the socioeconomic status.

In Germany, life expectancy and quality of life are heavily dependent on income, level of education and occupation (Lampert and Kroll 2010). Differences in income and the proportion of poor people in Germany have increased more rapidly in recent years than in most other 'Organisation for Economic Cooperation and Development (OECD)' countries (Organisation for Economic Cooperation and Development 2008). The OECD country comparison (2008) has also shown that social disadvantage and poverty have become less of a problem for the elderly, but increasingly for young people and young families. Gebken (2005) accordingly found that social disadvantage and poverty occur particularly in young families with several children, with just one parent earning an income, with single parents and in migrant families.

Data from the Socioeconomic Panel (SOEP) in 2008 showed that $21 \%$ of $13-18$-year olds are under particular threat of poverty. By comparison, the rate for the population 
as a whole was $14 \%$. These $13-18$ year-olds, together with 19-25 year-olds, represented the group most at risk of poverty. At $26.7 \%$, eastern Germany has a particularly high poverty rate compared to $16.8 \%$ in the old Federal States. In western Germany, Bremen has the highest poverty rate at $33 \%$. Compared across the EU, Germany's poverty rate of $15 \%$ for $0-17$-year olds in 2008 was above the average poverty rate for Denmark (9\%), Finland (11\%) and Sweden $(12 \%)$ and below that of France $(17 \%)$, the United Kingdom (23\%) and Italy (25\%; Laubstein et al. 2010).

The health status of socially disadvantaged children and adolescents in Germany

The development of diseases and mental disorders in childhood and adolescence results from a series of biological, mental and social risk factors. The context in which illness originates is complex and influenced by existing coping mechanisms and resources. The social situation of families in which children and young people grow up can be a significant risk factor affecting both their health status and their attitudes and behaviours relevant to health (Richter 2005).

Recent health surveys showed that children and adolescents in Germany suffer primarily from chronic diseases and psychological stress. According to the 'Kinder- und Jugendgesundheitssurvey'-KiGGS: health survey for children and adolescents in Germany-conducted by the Robert-Koch-Institut, $14 \%$ of the children and young people surveyed, suffer from chronic diseases (e.g. asthma or neurodermatitis) or developmental disorders (Scheidt-Nave et al. 2007). The BELLA study (Mental Health survey for children and adolescents in Germany) found $12 \%$ of mental abnormalities and $10 \%$ of more severe mental abnormalities among this age group (Ravens-Sieberer et al. 2007).

Socially disadvantaged children are at a higher risk for health and developmental problems. As KiGGS revealed, 36 -year olds from families with a low socioeconomic status suffered twice as often from mental and functional developmental disorders than their peers from families with a high socioeconomic status (Schlack 2008; Lampert and Kurth 2007). Also overweight and obesity is found three times more frequently among children and adolescents with a low socioeconomic status (Schlack 2008).

Differences in socioeconomic status can affect the health and development of children, even before birth. Inadequate and poor diets, consumption of tobacco, alcohol or drugs (Henkel 2007), consumption of prescription drugs or infections of the mother during pregnancy are associated with particular social classes and represent enormous risks for the development of the foetus (Spencer 2006; Lampert and Burger 2004). These antenatal, perinatal and postnatal complications may lead to premature birth and to low birth weight (Ellsäßer et al. 2002; Lampert and Kurth 2007).

According to the 'Sachverständigenrat zur Begutachtung im Gesundheitswesen' (Expert council for health assessment), one fifth of all newborns in Germany in 2009 grew up with considerable psychosocial stress, among other problems, and a severe lack of material and social resources. The social situation of their parents makes these children vulnerable to subsequent health damage.

The Health Behaviour in School-aged Children (HBSC) study by the World Health Organisation for Germany showed the negative effects of a low social status on subjective estimates of health. Eleven, 13 and 15 year-old boys and girls from higher income families attending a Gymnasium secondary school were better at assessing their own health than boys and girls from other secondary schools and lower income families. Young people from prosperous families furthermore reported healthier lifestyles (e.g. consumption of fruits and vegetables and fewer sugary drinks) than those from families with a low socioeconomic status. Children with a migration background, which is closely linked to a low socioeconomic status, were more frequently overweight, suffered from psychosomatic disturbances and a lower level of mental well-being than children with no background of migration (Erhart et al. 2008).

Lampert and Kurth (2007) reported further health risks related to a low socioeconomic status including dental health (Splieth et al. 2006), developmental disorders and disabilities (Borgetto 2010) as well as excessive weight and obesity (Erhart et al. 2008). Psychosocial outcomes such as behavioural disorders (Klocke 1996; Klocke and Hurrelmann 1995), eating disorders (Erhart et al. 2008) or experiences of violence (Pfeiffer et al. 1999) were also found.

The need for behavioural and structural prevention

Attitudes and behaviours relevant to health are formed early on in childhood and adolescence and develop into relatively stable behaviours in adults (Dragano et al. 2010; Yang et al. 2007). Young people are particularly at risk for many unhealthy behaviours such as the consumption of alcohol and tobacco (Currie et al. 2008), lack of physical activity (Kahn et al. 2008; van Mechelen et al. 2000) or an unhealthy diet (Wang et al. 2008).

Studies on the consumption of tobacco found that the majority of smokers started smoking before coming of age (e.g. Lampert and Burger 2005). Kuntz and Lampert (2010) conclude from this fact that children and young people who are prevented from smoking before coming of age, will not start smoking as adults either. Furthermore, KiGGS showed that about $15 \%$ of children and young people in Germany are overweight and some $6 \%$ are affected by obesity. 
Children and young people from socially disadvantaged populations and from families with a migration background suffer particularly from overweight and obesity. Although there are approaches involving primary and secondary preventive measures for obesity, only a few of these are aimed at socially disadvantaged children and young people (Möbus et al. 2005). This clearly shows the need for preventive measures that reach children and adolescents at risk.

The problem of not reaching relevant target groups in prevention research is called 'prevention paradox' (Hurrelmann 2003) or 'prevention dilemma' (Bauer 2005). Prevention programs addressing only health-related behaviours of children and adolescents (behavioural prevention) are often confronted with this dilemma. The efficiency of these prevention programs is limited, as they frequently fail to include those children and adolescents mostly in need for help (Bittlingmayer and Hurrelmann 2006). Prevention programs have to go beyond individual health behaviours and include the social settings of children and adolescents such as family, local community, nursery and school (structural prevention). According to the setting approach the social context has a significant impact on the perception of health, health strains and health resources. Thus, in the examination of socially disadvantaged children and adolescents, it emphasizes both behavioural and structural prevention (Bundesministerium für Gesundheit 2010). The following sections provide a brief overview of health promotion strategies in Europe to achieve health equity and focus then on Germany and its prevention initiatives for socially disadvantaged children and adolescents.

\section{Main Part}

Health inequalities in Europe

In spite of continuous improvement in the average state of health in Europe over recent decades, substantial health differences between European countries and between more and less socially disadvantaged classes within European countries remain. The expansion of the European Union has contributed to these differences and reinforced the concern about the social determinants of health. The rates of both mortality and morbidity are higher in socially disadvantaged groups of the population who have a lower level of education, fewer professional qualifications and lower income (Mackenbach 2006).

As has been clarified in previous parts, inequalities in health start early in life and persist (Wilkinson and Marmot 2003). Mackenbach's health report on Europe (2006) showed that children from families with a lower social class have on average lower birth weights and are more often born prematurely or with congenital anomalies. Also death rates are higher from conception onwards and continue throughout childhood. The examination of subjective health among European adolescents in the HBSC study revealed the disadvantageous impact of a low socioeconomic status beyond childhood. Thirteen and 15-year-old female adolescents from families with a medium or low socioeconomic status (measured by low familial affluence) had a higher chance for poor/ fair general health, low life satisfaction and multiple recurrent health complaints (Ravens-Sieberer et al. 2009). These results confirm the findings from other international studies such as the KIDSCREEN survey (von Rueden et al. 2006).

Mackenbach (2006) states three explanatory factors which mediate between low socioeconomic position and the risk of ill-health including material factors (e.g. housing conditions, working conditions or financial problems), psychosocial factors (e.g. social support, social integration, or psychosocial stressors) and health related behaviours (e.g. smoking, alcohol consumption or obesity). While Mackenbach points out that mentioning these factors does not exclude other potential influences, he emphasizes their interconnectedness. Similarly, Ravens-Sieberer et al. (2009) discuss access to material resources (e.g. the family's possession of a car, having one's own bedroom or going on holidays) and inappropriate reactions to stress (which might result in disturbed relationships or inner-familial conflicts) as mechanisms linking the socioeconomic status to adolescents' well-being. These are important and interlinked determinants of adolescents' health.

The results from these cross-national studies in Europe further confirm why prevention efforts should not be limited to individual behaviour. Health promotion efforts should include the individual and the setting from early stages.

European strategies to tackle health inequalities

The growing interest of the European Union (EU) in health equity is represented in both its new Health Strategy and Public Health Programme. Together for Health Strategy (2008-2013) identifies the reduction of health inequalities between and within member states as an important goal within the framework of the strategy's first principle of 'shared health values' (European Commission 2007). Also, the EU's new Public Health Programme (2008-2013) states that 'the attainment of a high level of physical and mental health and well-being and greater equality in health matters throughout the Community' (European Council 2007a). However, the EU's efforts to tackle inequalities in health are not limited to health policies.

In 2000, the EU passed the Lisbon strategy acknowledging the importance of poverty reduction and elimination of social exclusion (Judge et al. 2006). Social justice and social inclusion policies deal with the underlying causes of poor health and are, thus, very relevant for reducing health inequalities (Crombie et al. 2005). Judge et al. (2006) 
emphasize in their report on health inequalities in Europe that anti-poverty policies and policies on promoting social inclusion are crucial for reducing health inequalities and that countries are faced with the challenge of integrating these. Thus, the Lisbon European Summit had an important impact on health equity despite not directly referring to it, particularly, as it led to the 'National Action Plan against Poverty and Social Exclusion' which was developed in all $25 \mathrm{EU}$ countries (EuroHealthNet 2004). Following these leads, the EU launched its new strategy Europe 2020 for smart, sustainable and inclusive growth in 2010 and acknowledged that fighting inequalities is a prerequisite for growth and competitiveness. This strategy aims to move 20 million people out of poverty by 2020 .

As these strategies clarify, the EU supports inter-sectoral collaboration to achieve health equity. By adopting the Health in All Policies conclusion in 2006, the Council of the European Union further urged both EU institutions and member states to integrate health considerations in their nonhealth policies and legislation (The Council of the European Union 2006). The review of Judge et al. (2006) showed that entry points for policies on reducing health inequalities in European countries differ. Considering the lack of clear and measurable health equity policies in some countries, crosssectoral engagement becomes even more significant.

Germany has started to include the reduction of health inequalities as a specific aim in its national policies on child and adolescent health.

German initiatives for health equity among socially disadvantaged children and young people

The 'Strategie zur Förderung der Kindergesundheit' (the national government strategy for promoting child health) was launched in 2008 and is committed to achieving its key objectives by 2012. The strategy's overarching aims include promoting equity in health chances, improving general requirements for a healthy lifestyle, reducing health risks, supporting a healthy physical and mental development and creating sustainable public awareness for child and adolescent health. Prevention and health promotion is one of four central action fields. Furthermore, the importance of implementing preventive measures early (starting at pregnancy) and involving children's and adolescents' daily living environments is clarified (Bundesministerium für Gesundheit 2008).

Since 2000, the German health care law states that services on health promotion and prevention should contribute to the achievement of health equity. Equity in health was further one of the basic topics applied by the German Federal Ministry of Health and Social Security for agreeing on the 'Nationale Gesundheitsziele' (national health targets). The development of the cooperation association 'Nationale Gesundheitsziele' in 2000 provided a joint negotiating framework to bundle and provide specialist competence and knowledge in the health sector. Representatives of cost centres, service-providers, social partners, federal, state and local government policy, selfhelp and patient organizations, science and industry all work together in this framework. The national health objective 'Gesund aufwachsen' (Growing up healthy) in the field of child and youth health emphasizes life skills, physical activity and diet and was the first to be matched to an individual population and age group (Bundesministerium für Gesundheit 2010).

Revealing findings of the KiGGS study (Lampert and Kurth 2007) and the HBSC study (Erhart et al. 2008) on social determinants of child and adolescent health led to an update of the objective 'Gesund aufwachsen' in 2009. The objective was then included in national government health strategies and promotion programmes, such as the 'Strategie zur Förderung der Kindergesundheit' (Bundesministerium für Gesundheit 2010). The updated objective aimed on the one hand, to network various approaches to health and on the other hand, to highlight and deal with shortcomings of previous strategy and programme development. In this process, the cooperation association 'Nationale Gesundheitsziele' makes use of the World Health Organisation's setting approach (e.g. Franzkowiak and Sabo 1998; Großmann and Scala 2006). The setting approach for promoting the health of socially disadvantaged groups places equal emphasis on behavioural and structural prevention. Influencing both individual behaviour and social conditions is accordingly crucial. For child and adolescent health, this means that the settings family, local community, nursery and school have moved into focus.

The next section provides a brief overview of joint initiatives of the government, public health institutions and research institutions to promote the health of socially disadvantaged children and adolescents in Germany. While the National Centre on Early Prevention launched a programme to support socially disadvantaged families with children up to the age of three, the Federal Centre for Health Education and the Cooperation for Sustainable Prevention Research cover childhood and adolescence. The Cooperation for Sustainable Prevention Research has further taken the challenge to establish sustainable structures for successful prevention studies (capacity building).

The cooperation association 'Gesundheitsförderung bei sozial Benachteiligten'

The cooperation association 'Gesundheitsförderung bei sozial Benachteiligten' (Health Promotion for the Socially Disadvantaged) was initiated by the 'Bundeszentrale für Gesundheitliche Aufklärung' (BZgA - Federal Centre for Health Education) in 2003 and includes different agents from the healthcare sector such as the $\mathrm{BZgA}$ itself, health insurance companies, national and regional health organizations, health 
associations and charities, and representatives from political spheres and scientific institutions.

This cooperative association aims to provide better and more efficient prevention for people who are in particular need of health promotion due to their social status. Its work is based on a continuously updated database with information about good practice projects, good practice dialogues between researchers and practitioners (to encourage participatory quality development) and regional hubs for project coordination on a federal, state and local level.

The work of the cooperation association on socially disadvantaged children and adolescents aims to strengthen the government's strategy on child health promotion and the national health objectives. Results of good practice projects confirm the importance of an early implementation of prevention programmes for sustainable efficiency and the need for prevention programmes that are embedded in children's and adolescents' living environments such as family, nursery and school.

Based on these experiences and the knowledge of all collaborating partners within the cooperation, 'Allgemeine Handlungsempfehlungen für ein gesundes Aufwachsen für alle' (General recommendations for action on a healthy growing-up for all) were developed (2011). The recommendations for action are outlined below:

\section{Participation of children, young people and parents in} all phases of prevention: The participation of children and families enables the inclusion of their specific resources and strains in the planning, implementation and evaluation of prevention programmes.

2. Systematic networking of services in local communities: Local communities should network and support the interdisciplinary collaboration of different areas including health, child and youth assistance, education, family support and social services. This collaboration enables services for every stage of child development. Local community chains of prevention reduce risks on the transition to new phases of life such as the move from nursery to primary school or from secondary school to vocational training.

3. Low-threshold services in settings: Low-threshold services in the local community, at nursery and at school serve to build up social networks. Behavioural and structural prevention approaches are combined most meaningfully here for a sustainable preventive effect, to support those affected and to build up and maintain behaviour which promotes health.

4. Empowerment approaches: Services to reinforce competence, which link to family resources and support families professionally, increase parent competence.

5. Use of multipliers: Working with people who belong to the migrant community and/or are part of the local community structure, so called 'multipliers', is particularly suitable for reaching migrant families and women.
6. Qualification of volunteers: Specific qualification should be obtained by volunteers involved in health promotion. Their work should be coordinated, supervised and recognized.

7. Sustainable health promotion by applying the setting approach: Sustainable health promotion is reached by combining behavioural prevention and social prevention and by the active involvement of relevant target groups in changing their living environments.

These quality criteria are met in successful good practice projects such as 'Monheim für Kinder' (MoKi, Monheim for Children). MoKi started as a prevention project for socially disadvantaged families in 2002 and was integrated in the youth aid structures of the city of Monheim in 2005 (capacity building). MoKi represents a local community prevention chain for socially disadvantaged families supporting them during pregnancy, nursery and also at school and/or apprenticeship (Schlevogt and Nowak 2007). The project uses the nursery as a low-threshold setting to reach the target group including children, parents and nursery staff. All of them are involved in the prevention measure. Parents for example are supported throughout institutional transitions of their children and difficult circumstances and thereby, strengthened in their child-raising skills. MoKi emphasizes close networking with diverse facilities such as nursery, child and family facilities, consultant services, schools and local authorities to achieve sustainable prevention and health promotion (Kooperationsverbund Gesundheitsförderung bei sozial Benachteiligten 2011).

The national programme 'Frühe Hilfen für Eltern und Kinder und Soziale Frühwarnsysteme'

The 'Nationales Zentrum Frühe Hilfen' (NZFH, National Centre on Early Prevention) was established by the Federal Ministry of Family Affairs, Senior Citizens, Women and Youth in 2007 as part of the governmental programme 'Frühe Hilfen für Eltern und Kinder und Soziale Frühwarnsysteme' (Early Prevention and Intervention for Parents and Children and Social Early Warning Systems). The responsible bodies of the NZFH are the BZgA and the 'Deutsches Jugendinstitut' (DJI, German Youth Institute). The early childhood prevention initiative aims to ensure the healthy development of children in troubled families and disadvantageous social environments (with a focus on the 0-3 age group). Families under high stress are supported early during pregnancy and around the time of birth. In line with the EU's approach of integrity in health equity, the NZFH is based on the idea of integrating health services, child and youth health services and other services (e.g. the pregnancy and parenting advisory services) to promote child health as well as to prevent abuse and neglect in particular.

The government identified the 'requirements' or 'quality dimensions' of early prevention in its programme 'Frühe 
Hilfen für Eltern und Kinder und Soziale Frühwarnsysteme'. These mark best strategies for supporting troubled families in their daily life, particularly, child-raising and, hence, prevent health risks to children. The quality dimensions pertain to the following:

1. Ensuring systematic and comprehensive access to the target group

2. Systematic and objective identification of risk

3. Motivating families to active participation in support services

4. Adapting support services to the needs of families

5. Monitoring the support provision process

6. Inter-agency networking and compulsory cooperation between actors

7. Embedding early prevention in the regulatory system

Research is needed to determine necessary practical requirements to meet these quality standards. Thus, the NZFH carried out 10 pilot projects of which several evaluate the work of midwives (as a low-threshold form of support which is well accepted by families), others focus on specific and needs-based support and one project examined existing early prevention services in the federal states of North Rhine-Westphalia and Schleswig-Holstein. These projects have not all been finished yet, but first results of a crossproject survey with questions about the aforementioned quality dimensions are available.

The majority of the project teams mentioned their cooperation with child and youth welfare offices, pregnancy counselling centres and midwives as the most successful. Systematic and objective risk measurement still faces practical challenges and requires further development, but there was broad consensus on applying standardized measures. The significance of trust-building measures was emphasized. Moreover, accessing services should be voluntarily and not cause extra costs for the families. People who already know the family well (e.g. paediatrician or midwife) are useful for motivating families to participate. Considering the forth quality standard, the necessity of participative procedures was mentioned. Ongoing monitoring is essential and facilitated by maintaining personal contacts or joint appointment arranging. Finally, project experiences showed that the inter-agency networking was regulated best by an agreement and that projects have to be embedded in the regulatory system to achieve sustainability (Renner and Heimeshoff 2011).

Networking project 'Cooperation for sustainable prevention research'

In 2004, the 'Bundesministerium für Bildung und Forschung' (BMBF, German Ministry for Education and Research) set up for the first time targeted funding for prevention research to intensify the scientific and empirical basis of primary prevention and health promotion. In the time period from 2004-2012, 60 projects have and will be funded in four phases. The close collaboration of over 50 scientific institutions and 170 practising partners in project planning and implementation intends to ensure relevance for practice. The ministry aims to avoid widespread health risks and diseases and to reinforce health promotion. Socially disadvantaged children and young people are a particularly important target group of this research focus. The projects cover the following:

- Developing and testing new concepts, programmes and access routes

- Evaluating the (cost) effectiveness of measures

- Contributing to the development of methods

- Promoting quality assurance and capacity-building

The umbrella project 'Kooperation für nachhaltige Präventionsforschung' (KNP-Cooperation for sustainable prevention research) was set up in 2009 to support the meaningful processing and application of key knowledge from this BMBF funding focus on prevention research and to promote networking between science, practice and politics.

Thirty-six of the 60 BMBF projects examine prevention and health promotion among socially disadvantaged children and adolescents. The funded projects implement and evaluate prevention programmes on children's and adolescents' illhealth behaviours in their social settings; as for example, in a project on the prevention of obesity among socially disadvantaged children (Warschburger 2010). The research team dealt with the problem that most nutritional programs of prevention among obese children from families with a low social status are not effective. According to the setting approach, the social setting 'family' was involved to tackle the problem. Results showed that most parents do not perceive their children as overweight or obese and thus, parents (the family context) have to be included as an important factor in the development and implementation of prevention programs (Warschburger 2010). Access to all 36 projects is provided online at the KNP database (http://www.knp-forschung.de/).

\section{Conclusion}

The health promotion of socially disadvantaged children and adolescents has moved into political focus in recent years. Health surveys revealed inequalities in health among children and adolescents in Europe (Ravens-Sieberer et al. 2009) and in Germany (Richter 2005). Following these findings, decisionmakers have acknowledged the social determinants of child and youth health as well as the importance of early preventive measures in their policies and strategies.

Mackenbach (2006) described in his European health report the interconnectedness of material factors, psychosocial factors and health related behaviours in mediating the socioeconomic 
status to health. Hence, prevention strategies addressing merely ill-health behaviour will have limited effects and should include factors also related to individuals' living environments. Furthermore, the systematic exchange of experiences in fighting health inequalities between European countries can increase their learning speed. The EU facilitated this process by establishing the Expert Working Group on Social Determinants of Health Inequalities and collaborating with international health organizations such as the WHO (Mackenbach 2006; Judge et al. 2006). In Germany, the importance of both behavioural and structural prevention has been acknowledged and operationalized in prevention initiatives. Projects from the BZgA, NZFH and KNP apply the setting approach to create sustainable structures for prevention efforts and thereby, capacity building.

Capacity building in prevention means moving away from many time-limited projects towards projects based on empirical findings which adopt and implement concepts having been evaluated as effective. In this context, the question of how to organize individual prevention programmes to one regional help system gains increasing importance, emphasizing the concept of community resilience (e.g. Wolkow and Ferguson 2001). As has been shown in the good practice project MoKi, preventive community chains have to be established to ensure services at every stage of children's and adolescents' development. This sustainable good practice project further clarified the importance of inter-agency networking.

Improving the health of children and young people in socially disadvantaged families cannot be assigned to a specific political field, but should be considered a crosscutting requirement (Kuntz and Lampert 2010). Cooperation between healthcare, educational and social services sectors allows socially disadvantaged children to be reached and supported more efficiently (Altgeld and Kolip 2004).

In sum, approaches such as capacity building and local community chains of prevention have to receive further political attention to achieve sustainable prevention effects. The development of new methodology in health promotion research such as the "parallel tracking of bottom up and top down programmes' (Laverack 2008) or 'participatory quality development' (Wright 2010), facilitates their operationalization and evaluation.

\section{References}

Altgeld T, Kolip P (2004) Konzepte und Strategien der Gesundheitsförderung. In: Hurrelmann K, Klotz T, Haisch J (eds) Lehrbuch Prävention und Gesundheitsförderung. Huber, Bern, pp 41-51

Bauer U (2005) Das Präventionsdilemma: Potenziale schulischer Kompetenzförderung im Spiegel sozialer Polarisierung. VS Verlag, Wiesbaden, Germany

Biermann H, Rützel J (1999) Didaktik der beruflichen Bildung Benachteiligter. In: Biermann H, Bonz B, Rützel J (eds) Beiträge zur Didaktik der Berufsausbildung Benachteiligter. Holland und Josenhans, Stuttgart, Germany, pp 11-37
Bittlingmayer UH, Hurrelmann K (2006) Präventionsstrategien für sozial Benachteiligte: das Beispiel der schulischen Suchtprävention und Skillförderung. In: Kirch W, Badura B (eds) Prävention. Ausgewählte Beiträge des Nationalen Präventionskongresses Dresden, 1. und 2. Dezember 2005. Springer, Heidelberg, pp 173-192

Borgetto B (2010) Sprache - Bildung - Gesundheit: ein kritischkonstruktiver Blick auf Chancen und Praxis der Sprachstandserhebung bei Kindern im Vorschulalter. Publ Health Forum 18:2324. doi:10.1016/j.phf.2010.09.011

Bundesministerium für Gesundheit (2008) Strategie der Bundesregierung zur Förderung der Kindergesundheit. Referat für Öffentlichkeitsarbeit, Berlin

Bundesministerium für Gesundheit (2010) Nationales Gesundheitsziel: Gesund aufwachsen-Lebenskompetenz, Bewegung, Ernährung. Referat für Öffentlichkeitsarbeit, Berlin

Currie C, Gabhain S, Godeau E, Roberts C, Smith R, Curie D, Pickett W, Richter M, Morgan A, Barnekow V (2008) Inequalities in young people's health. HBSC international report from the 2005/ 2006 survey. WHO Regional Office for Europe, Copenhagen

Crombie IK, Irvine L, Elliott L, Wallace H (2005) Closing the health enequalities gap: an international perspective. WHO Regional Office for Europe, Copenhagen

Dragano N, Lampert T, Siegrist J (2010) Wie baut sich soziale und gesundheitliche Ungleichheit im Lebenslauf auf? In: Sachverständigenkommission 13. Kinder- und Jugendbericht (ed) Materialien zum 13. Kinder- und Jugendbericht:ehr Chancen für gesundes Aufwachsen. Verlag Deutsches Jugendinstitut, München, pp 11-50

Ellsäßer G, Böhm A, Kuhn J, Lüdecke K, Rojas G (2002) Soziale Ungleichheit und Gesundheit bei Kindern: Ergebnisse und Konsequenzen aus den Brandenburger Einschulungsuntersuchungen. Kinderärzt Praxis 73:248-257

Erhart M, Ottava V, Nickel J, Richter M, Hurrelmann K, Klocke A, Melzer W, Ravens-Sieberer U (2008) Gesundheit, Jugend und sozialer Kontext: Ergebnisse der zweiten HBSC Jugendgesundheitsstudie in Deutschland. Pädagog J 010/08

EuroHealthNet (2004) Health and social inclusion in the context of Lisbon, Brussels. http://www.eurohealthnet.org. Cited 15 November 2011

Franzkowiak P, Sabo P (1998) Dokumente der gesundheitsförderung. Mainz/Schwabenheim 2. unveränd. Auflage. Fachverlag Peter Sabo, Mainz/Schwabenheim

Gebken U (2005) Sozialbenachteiligte Kinder und Jugendliche im Sport: Forschungsstand, Erfahrungen und didaktische Empfehlungen. Sportpädagogik Online. http://www.sportpaedagogikonline.de/neu2005.html. Cited 26 July 2011

Großmann R, Scala K (2006) Gesundheit durch Projekte fördern: ein Konzept zur Gesundheitsförderung durch Organisationsentwicklung und Projektmanagement, 4th edn. Juventa, Weinheim, München

Henkel D (2007) Sucht und soziale Lage. In: Deutsche Hauptstelle für Suchtfragen e.V (ed) Jahrbuch Sucht 2007. Neuland, Geesthacht, Germany, pp 179-192

Hurrelmann K (2003) Gesundheitssoziologie: eine Einführung in sozialwissenschaftliche Theorien von Krankheitsprävention und Gesundheitsförderung. Juventa, München

Iben G (1997) Soziale Benachteiligung. In: Deutscher Verein für öffentliche und private Fürsorge (ed) Fachlexikon der sozialen Arbeit. Eigenverlag, Frankfurt am Main, 845 pp

Judge K, Platt S, Costongs C, Jurczak K (2006) Health inequalities: a challenge for Europe. An independent, expert report commissioned by the UK presidency of the EU (February 2006), EU, Brussels

Kahn JA, Huang B, Gillman MW, Field AE, Austin SB, Colditz GA, Frazier AL (2008) Patterns and determinants of physical activity in U.S. adolescents. J Adolesc Health 42(4):369-377. doi: 10.1016/j.jadohealth.2007.11.143 
Klocke A (1996) Aufwachsen in Armut. Auswirkungen und Bewältigungsformen der Armut im Kindes- und Jugendalter. Zeitschr Sozialisationsforsch Erziehungssoziol 16:390-409

Klocke A, Hurrelmann K (1995) Armut und Gesundheit: Inwieweit sind Kinder und Jugendliche betroffen? Zeitschr Gesundheitswissenschaf 2:138-151

Kooperationsverbund Gesundheitsförderung bei sozial Benachteiligten (2011) Gesundheitschancen bei sozial benachteiligten Kindern und Jugendlichen nachhaltig verbessern. http:/www.gesundheitlichechancengleichheit.de/gesundheitsfoerderung-bei-kindern-undjugendlichen/handlungsempfehlungen/. Cited 27 July 2011

Kuh D, Ben-Schlohmo Y (2005) A life course approach to chronic disease: epidemiology. Oxford University Press, Oxford

Kuntz B, Lampert T (2010) Soziale Unterschiede im Gesundheitsverhalten Jugendlicher: Anforderungen an eine sozial-sensitive Präventionspolitik. Public Health Forum 18:9-10. doi:10.1016/j.phf. 2010.09.003

Lampert T, Burger M (2004) Rauchgewohnheiten in Deutschland: Ergebnisse des telefonischen Bundesgesundheitssurveys. Gesundheitswesen 66:511-517. doi:10.1055/s-2004-813527

Lampert T, Burger M (2005) Verbreitung und Strukturen des Tabakkonsums in Deutschland. Bundesgesundheitsblatt 48:1231-1241. doi:10.1007/s00103-005-1158-7

Lampert T, Kurth B (2007) Sozialer Status und Gesundheit von Kindern und Jugendlichen: Ergebnisse des Kinder- und Jugendgesundheitssurveys. Deutsches Ärzteblatt 104:2944-2949

Lampert T, Kroll LE (2010) Armut und Gesundheit. GBE Kompakt Robert Koch-Instituts, Berkin, vol 5, pp 1-9

Laubstein C, Dittmann J, Holz G (2010) Jugend und Armut Forschungsstand sowie Untersuchungsdesign der AWO-ISS-Langzeitstudie "Kinder- und Jugendarmut IV". Zwischenbericht 2010, Spiegler, Frankfurt am Main

Laverack G (2008) Berücksichtigung des Empowerments in der Programmplanung von Gesundheitsförderung. Gesundheitswesen 70:736-741. doi:10.1055/s-0028-1103259

Mackenbach JP (2006) Health inequalities: Europe in profile. An independent, expert report commissioned by the UK Presidency of the EU (February 2006), EU, Brussels

Möbus S, Hoffmann B, Merkel-Jens A (2005) Adipositasprogramme: (k)eine Hilfe für sozial benachteiligte Kinder und Jugendliche? Wirtschaftverlag NW, Bremerhaven, Germany

Organisation for Economic Cooperation and Development (2008) Are we growing unequal? New evidence on changes in poverty and incomes over the past 20 years. http://www.oecd.org/dataoecd/48/ 56/41494435.pdf. Cited 26 July 2011

Pfeiffer C, Wetzels P, Enzmann D (1999) Innerfamiliäre Gewalt gegen Kinder und Jugendliche und ihre Auswirkungen. Kriminologisches Forschungsinstitut Niedersachsen. Forschungsberichte Nr.80. http:// www.kfn.de/Publikationen/KFN-Forschungsberichte.htm. Cited 26 July 2011

Power C, Kuh D (2006) Life course development of unequal health. In: Siegrist J, Marmot M (eds) Social inequalities in health: new evidence and policy implications. Oxford University Press, Oxford, pp 27-54

Ravens-Sieberer U, Torsheim T, Hetland J, Vollebergh W, Cavallo F, Jericek H, Alikasifoglu M, Valimaa R, Ottova V, Erhart M, the HBSC Positive Health Focus Group (2009) Subjective health, symptom load and quality of life of children and adolescents in Europe. Int J Public Health 54:151-159. doi:10.1007/s00038009-5406-8

Ravens-Sieberer U, Wille N, Bettge S, Erhart M (2007) Psychische Gesundheit von Kindern und Jugendlichen in Deutschland: Ergebnisse aus der BELLA-Studie im Kinder- und Jugendgesund- heitssurvey (KiGGS). Bundesgesundheitsbl Gesundheitsforsch Gesundheitsschutz 50:871-878. doi:10.1007/s00103-007-0250-6

Renner I, Heimeshoff V (2011) Pilot projects in the German federal states: summary of results. National Centre on Early Prevention, Cologne, Germany

Richter M (2005) Die Bedeutung von sozialer Ungleichheit für die Gesundheit im Jugendalter. Gesundheitswesen 67:709-718. doi:10.1055/s-2005-858652

Scheidt-Nave C, Ellert U, Thyen U, Schlaud M (2007) Prävalenz und Charakteristika von Kindern und Jugendlichen mit speziellen Versorgungsbedarf im Kinder- und Jugendgesundheitssurvey (KiGGS) in Deutschland. Bundesgesundheitsbl Gesundheitsforsch Gesundheitsschutz 50:750-756. doi:10.1007/s00103-007-0237-3

Schlack HG (2008) Wie (un)gesund sind Kinder in Deutschland? Fakten, Einschätzungen, Handlungsbedarf. Frühförder Interdisziplinär 27:147-154

Schlevogt V, Nowak I (2007) Best Practice Familienzentrum: MoKiMonheim für Kinder-das Familienzentrum der fünf Kindertagesstätten im Berliner Viertel. Jugendamt der Stadt Monheim am Rhein, Frankfurt am Main, Monheim

Spencer N (2006) Explaining the social gradient in smoking in pregnancy: early life course accumulation and cross-sectional clustering of social risk exposures in the 1958 British National Court. Soc Sci Med 62:1250-1259

Splieth CH, Heydruck C, König KG (2006) Gruppenprophylaxe nach dem Caries Decline. Oralprophylaxe Kinderzahnheilkunde 28:60-64

The Council of the European Union (2006) Council conclusions on Health in All Policies (HiAP). Proceeding of the 2767th Employment, Social Policy, Health and Consumer Affairs Council meeting. Brussels, Nov 30-Dec 12006

The European Commission (2007) White paper: together for health: a strategic approach for the EU 2008-2013. EC, Brussels, 630 pp

The European Council (2007a) DECISION No. 1350/2007/EC of the European Parliment and of the Council of 23 October 2007 establishing a second programme of Community action in the field of health (2008-2013). The European Council, Brussels

van Mechelen W, Twisk JW, Post GB, Snel J, Kemper HC (2000) Physical activity of young people: the Amsterdam Longitudinal Growth and Health Study. Med Sci Sports Exerc 32(9):1610-1616

von Rueden U, Gosch A, Rajmil L, the European KIDSCREEN group (2006) Socioeconomic determinants of health related quality of life in childhood and adolescence: results from a European study. J Epidemiol Community Health 60:130-135. doi:10.1136/jech. 2005.039792

Wang YC, Bleich SN, Gortmaker SL (2008) Increasing caloric contribution from sugar-sweetened beverages and $100 \%$ fruit juices among US children and adolescents, 1988-2004. Pediatrics 121:1604-1614. doi:10.1542/peds.2007-2834

Warschburger P (2010) Prävention kindlicher Adipositas: Was beeinflusst die Inanspruchname von Präventionsangeboten? Public Health Forum 18(4):14.e1-14.e3. doi:10.1016/j.phf.2010.09.006

Wilkinson R, Marmot M (2003) The solid facts. WHO Regional Office for Europe, Copenhagen

Wolkow KE, Ferguson HB (2001) Community factors in the development of resiliency: considerations and future directions. Community Ment Health J 37:489-498. doi:10.1023/A:1017574028567

Wright MT (2010) Partizipative Qualitätsentwicklung in der Gesundheitsförderung und Prävention. Huber, Bern

Yang X, Telama R, Leskinen E, Mansikkaniemi K, Viikari J, Raitakari OT (2007) Testing a model of physical activity and obesity tracking from youth to adulthood: the cardiovascular risk in young Finns study. Int J Obes 31(3):521-527. doi:10.1038/sj.ijo.0803459 